\title{
Novel multi-biotin grafted poly(lactic acid) and its self-assembling nanoparticles capable of binding to streptavidin
}

This article was published in the following Dove Press journal:

International Journal of Nanomedicine

27 January 2012

Number of times this article has been viewed

\author{
Hao Yan ${ }^{1,2}$ \\ Weimin Jiang ${ }^{1,2}$ \\ Yinxing Zhang ${ }^{1,2}$ \\ Ying Liu',2 \\ Bin Wang ${ }^{1,2}$ \\ Li Yang ${ }^{1,2}$ \\ Lihong Deng ${ }^{1,2}$ \\ Gurinder K Singh ${ }^{1,2}$ \\ Jun Pan ${ }^{1,2}$
}

'Bioengineering College, Chongqing University, ${ }^{2}$ Key Laboratory of Biorheological Science and Technology (Chongqing University), Ministry of Education, Chongqing, People's Republic of China
Correspondence: Jun Pan Bioengineering College, Chongqing University, Chongqing 400044, People's Republic of China Tel +862365102507 Fax +86 23 65I0 2507 Email panj@cqu.edu.cn
Abstract: Targeted drug delivery requires novel biodegradable, specific binding systems with longer circulation time. The aim of this study was to prepare biotinylated poly(lactic acid) (PLA) nanoparticles (NPs) which can meet regular requirements as well conjugate more biotins in the polymer to provide better binding with streptavidin. A biotin-graft-PLA was synthesized based on previously published biodegradable poly(ethylene glycol) (PEG)-graft-PLA, with one polymer molecule containing three PEG molecules. Newly synthesized biotin-graft-PLA had three biotins per polymer molecule, higher than the previous biotinylated PLA ( $\leq 1$ biotin per polymer molecule). A PEG with a much lower molecular weight (MW 1900) than the previous biotinylated PLA (PEG MW $\geq 3800$ ), and thus more biocompatible, was used which supplied good nonspecific protein-resistant property compatible to PEG-graft-PLA, suggesting its possible longer stay in the bloodstream. Biotin-graft-PLA specifically bound to streptavidin and self-assembled into NPs, during which naproxen, a model small molecule (MW $230 \mathrm{Da}$ ) and hydrophobic drug, was encapsulated (encapsulation efficiency 51.88\%). The naproxenloaded NPs with particle size and zeta potential of $175 \mathrm{~nm}$ and $-27.35 \mathrm{mV}$ realized controlled release within 170 hours, comparable to previous studies. The biotin-graft-PLA NPs adhered approximately two-fold more on streptavidin film and on biotin film via a streptavidin arm both in static and dynamic conditions compared with PEG-graft-PLA NPs, the proven nonspecific protein-resistant NPs. The specific binding of biotin-graft-PLA NPs with streptavidin and with biotin using streptavidin arm, as well as its entrapment and controlled release for naproxen, suggest potential applications in targeted drug delivery.

Keywords: targeted drug delivery, bioactive, biodegradable, poly(ethylene glycol) (PEG), controlled release, naproxen

\section{Introduction}

Biodegradable and specifically bioactive nanoparticles (NPs) are one of the promising routes to realize site-specific drug delivery for cancer or other diseased tissues. ${ }^{1-3}$ To enhance biodegradable NP bioactivity, various chemical modifications are performed on the polymers for NP preparation or directly on NPs, ${ }^{4-6}$ including (1) direct conjugation of targeting biomolecules, eg, antibodies, and (2) attachment of ligands or antibodies as arms and further combination with their corresponding central elements or receptors, antigens of ligands, or antibodies as targeting biomolecules. The second method is preferred as it maintains bioactivity of the targeting biomolecules to a larger extent. ${ }^{4-6} \mathrm{~A}$ widely applied ligand/receptor pair is biotin/streptavidin, owing to its high binding affinity $\left(\mathrm{K}_{\mathrm{d}}=10^{-15} \mathrm{M}\right)$. Even though streptavidin has been incorporated into polymers, ${ }^{7}$ biotin is more popular due to its simple structure, 
low molecular weight (MW), good reactivity with amine, and retained binding property with streptavidin postamination reaction. In addition, one biotin can easily combine with one of four biotin binding sites on tetrameric streptavidin, ${ }^{8,9}$ which allows further combination of various commercialized biotinylated proteins acting as targeted molecules. ${ }^{10}$ Furthermore, to increase the specific binding between biotin and streptavidin and circulation time of NPs in the body, some stealth chemicals, eg, poly(ethylene glycol) (PEG) $)^{11-13}$ and pluronic, ${ }^{14}$ have been linked to polymers or NPs prior to biotin attachment. These can further suppress cellular and protein absorption, ${ }^{15}$ as well as make polymers or NPs more water soluble.

Poly(lactic acid) (PLA), one of the few biodegradable polymers approved by the Food and Drug Administration, has long been applied in NP preparation. However, NPs of PLA have no bioactivity. Biotin/(Strept)avidin are the most popular molecules used to ascribe it bioactivity. Although several studies have reported conjugating biotin with PEGblock-PLA or pluronic-block-PLA materials, which selfassemble into NPs and target to steptavidin in vitro, 5,6,10,12,13,16-18 problems still exist: (1) no more than one biotin is attached to one PLA molecule, which limits the combination of NPs with streptavidin and their targeting function, and (2) the MW of PEG used is generally higher than 3800 in order to receive good protein resistance and self-assembly function of NPs. PEG cannot degraded in the body although it expresses low toxicity, ${ }^{19}$ which limits applications of NPs. ${ }^{20}$ In addition to the lack of bioactivity in PLA NPs, the large amount of residual organic solvent and surfactant added during preparation may harm cells. It was previously reported that synthesis of PEGgraft-PLA with low MW of PEG (MW 600-1900) and three linked PEGs per PLA molecule showed good nonspecific protein resistance and self-assembly properties in aqueous solution. ${ }^{21,22}$ PEG-graft-PLA (PEG MW 1900) encapsulated and realized controlled release of hydrophilic (insulin) and hydrophobic (naproxen) chemicals without surfactant and minimal use of organic solvent. ${ }^{22}$

In the current study, the aim was to improve specific binding of biotinylated PLA with streptavidin for application in targeted drug delivery by conjugating more than one biotin to one polymer molecule. It was hoped that the received polymer could self-assemble into NPs and entrap chemicals which combine specifically with streptavidin and biotin via a streptavidin arm (Figure 1). The biotin-graft-PLA was synthesized based on PEG-graft-PLA (MW 1900) and characterized. Self-assembly encapsulation and controlled

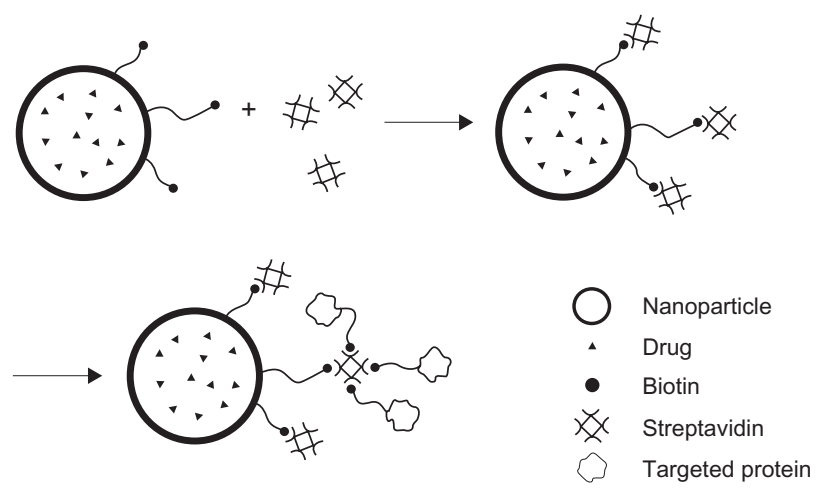

Figure I The combination of biotin-graft-poly(lactic acid) nanoparticles with streptavidin and with biotinylated protein via a streptavidin arm to realize targeted drug delivery.

release of naproxen, a small hydrophobic model medicine, were studied. Specific binding of biotin-graft-PLA and its self-assembled NPs with streptavidin and with biotin via a streptavidin arm were evaluated in vitro under static and dynamic conditions.

\section{Materials and methods Polymers and reagents}

Biotin, fluorescein 5-isothiocyanate (FITC)-conjugated streptavidin (FITC-streptavidin), N,N'-dicyclohexylcarbodiimide (DCC), and N-hydroxysuccinimide (NHS) were obtained from Thermo Fisher Scientific Inc (Rockford, IL). FITC-conjugated bovine serum albumin (FITC-BSA), pyrene, and $\mathrm{O}, \mathrm{O}^{\prime}$-bis-(2-aminopropyl) polypropylene glycol-block-polyethylene oxide-block-polypropylene glycol $\left(\mathrm{H}_{2} \mathrm{~N}-\mathrm{PEG}-\mathrm{NH}_{2}, \mathrm{MW} \sim 1900\right)$ were procured from Sigma-Aldrich Co (St Louis, MO). N-methylmorpholine was bought from Shanghai Hanhong Chemical Co, Ltd (Shanghai, China). PLA, 10\% maleic anhydride graft PLA, and PEG-graft-PLA were prepared in the lab as described previously. ${ }^{21,23}$ Briefly, PLA was synthesized by melt ringopen polymerization of D,L-lactide at $140^{\circ} \mathrm{C}$ for 24 hours under vacuum. Maleic anhydride graft PLA was prepared by bulk radical reaction initiated by benzoperoxide. PEG-graftPLA was obtained by amination of maleic anhydride graft PLA with $\mathrm{H}_{2} \mathrm{~N}-\mathrm{PEG}-\mathrm{NH}_{2}$ in tetrahydrofuran at $50^{\circ} \mathrm{C}-55^{\circ} \mathrm{C}$ for 1 hour followed by evaporation of solvent, which was a polymeric mixture with low dispersity.

\section{Synthesis and characterization of biotin-graft-PLA}

Biotin (0.14 g), DCC (0.353 g), and NHS (0.197 g) dissolved in $5 \mathrm{~mL} \mathrm{~N}, \mathrm{~N}$-dimethylformamide (DMF) were 
allowed to react at room temperature overnight. The product was centrifuged at $2000 \mathrm{rpm}$ for 5 minutes to remove white precipitate. The supernatant was precipitated with diethyl ether followed by four times recrystallization with isopropanol. A white and water soluble crystal of biotin NHS ester was received after vacuum drying. Biotin NHS (71 mg) was used to react with $0.5 \mathrm{~g}$ of PEG-graft-PLA at $40^{\circ} \mathrm{C}$ for 72 hours in $1 \mathrm{~mL}$ DMF. Excessive biotin NHS was removed by dissolving the products in distilled water twice. The product was vacuum-dried to yield a white and nontransparent solid biotin-graft-PLA, which was soluble in tetrahydrofuran, DMF, and dimethyl sulfoxide.

Ninhydrin assay was used to confirm the reaction and quantify the free amine content in PEG-graft-PLA and biotingraft-PLA according to the standard curve of $\mathrm{H}_{2} \mathrm{~N}-\mathrm{PEG}-\mathrm{NH}_{2}$ as described previously. ${ }^{21}$ The absorption of yielded purple matter was tested at $562 \mathrm{~nm}$ (Lambda 900 Spectrometer; PerkinElmer Inc, Waltham, MA). Differential scanning calorimetry measurements were carried out on a thermal analyzer (Q200 Differential Scanning Calorimeter; TA Instruments, New Castle, DE) at a heating rate of $5^{\circ} \mathrm{C} /$ minute from $0^{\circ} \mathrm{C}$ to $80^{\circ} \mathrm{C}$.

To evaluate the hydrophilicity, the advancing water contact angle was tested with sessile drop method (100-00-115 Contact Angle Goniometer; Ramé-Hart Instrument Co, Netcong, NJ). The surfactivity and possibility to encapsulate chemicals was assessed according to critical micelle concentration which was determined using established fluorescence method with pyrene as an extrinsic probe. ${ }^{24}$ Serial solutions with fixed pyrene concentration of $6.0 \times 10^{-7} \mathrm{M}$ and various concentrations of biotin-graftPLA between $5.0 \times 10^{-6} \mathrm{mg} / \mathrm{mL}$ and $5.0 \times 10^{-2} \mathrm{mg} / \mathrm{mL}$ were prepared. The excitation intensity of pyrene at $338 \mathrm{~nm}$ and $336 \mathrm{~nm}$ was obtained (LS 50B Fluorescence Spectrometer; PerkinElmer), according to the scanning excitation spectrum between $300 \mathrm{~nm}$ and $360 \mathrm{~nm}$, by fixing the emission spectrum at $395 \mathrm{~nm}$ and the excitation and emission bandwidth at $5 \mathrm{~nm}$. Critical micelle concentration was determined by taking the midpoint in the plot of the intensity ratio of 328/326 to the logarithm concentration of biotin-graft-PLA.

\section{Preparation and characterization of biotin-graft-PLA and PEG-graft-PLA NPs}

Pyrene- and naproxen-loaded NPs in biotin-graft-PLA or PEG-graft-PLA, which were respectively used to conduct specific binding and drug encapsulation tests, were prepared by self-assembly method. In brief, $10 \mathrm{mg}$ of biotin-graft-PLA or PEG-graft-PLA and $0.1 \mathrm{mg}$ of pyrene or $0.8 \mathrm{mg}$ of naproxen were dissolved in $1 \mathrm{~mL}$ acetone and dropped into $10 \mathrm{~mL}$ distilled water under constant stirring. After evaporation of acetone and centrifugation at $3000 \mathrm{rpm}$ to remove unloaded pyrene or naproxen, NPs were obtained. Native NPs were prepared with the same procedure but without pyrene and naproxen.

The morphology of various NPs was observed by a transmission electron microscope (Tecnai 10; Philips, Amsterdam, the Netherlands) at $80 \mathrm{kV}$ after staining with $2 \%$ sodium phosphotungstate for 3 minutes. Average size and zeta potential of NP solution were tested at room temperature by a dynamic light scattering instrument (Zetasizer Nano S90; Malvern Instruments Ltd, Malvern, UK) using argon ion laser. The stability of NPs under dilution (in aqueous solutions with phosphate buffered saline) or $\mathrm{pH}$ change (acidic and basic conditions) were studied based on the fact that the NPs dilute or encounter an acidic or basic environment besides the neutral condition when introduced into the body. It was delineated as average particle size and zeta potential change before and after dilution (10 or 100 times) or $\mathrm{pH}$ change ( 4.5 or 10.5 , adjusted with $0.1 \mathrm{~N}$ hydrochloride or sodium hydroxide, respectively).

To test the encapsulation efficiency of naproxen, the NPs were centrifuged at $3000 \mathrm{rpm}$. The sediment which contained unencapsulated and insoluble naproxen, but not the NPs, was collected and dissolved in DMF. The concentration of naproxen in DMF solution was tested at $331 \mathrm{~nm}$ (Lambda 900 Spectrometer; PerkinElmer) and used to calculate encapsulation efficiency according to the equation: (original naproxen added in NPs preparation - naproxen in precipitate - solubility of naproxen in water)/original naproxen added in NPs preparation. The cumulative release of naproxen was tested with dialysis method at $37^{\circ} \mathrm{C}$ and $150 \mathrm{rpm}$. Unencapsulated and insoluble naproxen $(5 \mathrm{~mL})$ was removed from NP solution by centrifuge and placed into a dialysis membrane (cutoff MW 8000), and $45 \mathrm{~mL}$ of $0.01 \mathrm{M}$ phosphate buffered saline was added as dialysis solution in a $100-\mathrm{mL}$ conical beaker. Dialysis solution $(1 \mathrm{~mL})$ was sampled and an equal amount of fresh phosphate buffered saline was supplemented at various time points. Naproxen concentration was tested at $331 \mathrm{~nm}$ where the biotin-graft-PLA had no absorbance and was used to calculate cumulative release, which was expressed as percentage change of naproxen amount in dialysis solution versus total entrapped naproxen over time. Each test was replicated at least three times. 


\section{Specific binding property of biotin-graft-PLA and its NPs} Specific binding of biotin-graft-PLA film with streptavidin

Before evaluation of specific binding between biotin-graftPLA NPs and streptavidin, the binding of streptavidin on biotin-graft-PLA film was tested. The amount of absorbed streptavidin and BSA on the surface of polymer films was tested. BSA was chosen as a representative nonspecific binding protein, due to the fact that albumin is the domination protein in human plasma when absorbed on PLA. ${ }^{11}$ The polymer film was formed on glass dish $(35 \mathrm{~mm})$ with $6 \mathrm{mg}$ of polymer dissolved in $2 \mathrm{~mL}$ ethyl acetate after evaporation of solvent in air ( $~ 80 \%$ humidity) or at $100 \%$ humidity for 96 hours. FITC-streptavidin ( $3 \mathrm{~mL}$ ) or FITC-BSA solution in dionized water $(0.02 \mathrm{mg} / \mathrm{mL})$ was added to glass dish and incubated at $37^{\circ} \mathrm{C}$ for 30 minutes before removal. The film was repetitively washed with dionized-water until fluorescent intensity was lower than 10, monitored by spectrofluorometer (LS-50B; PerkinElmer). The fluorescence on polymer film was observed with an inverted fluorescence microscope (Olympus IX71; Olympus Corporation, Tokyo, Japan) followed by spectrofluorometer (LS-50B; PerkinElmer) at $510 \mathrm{~nm}$ with $490 \mathrm{~nm}$ excitation after dissolving in $3 \mathrm{~mL}$ of tetrahydrofuran. The amount of absorbed FITC-streptavidin or FITC-BSA on the polymer film was calculated according to their fluorescent standard curves. PEG-graft-PLA was used as control material. Each absorption test was replicated three times.

\section{Specific binding of biotin-graft-PLA NPs to streptavidin and to biotin via streptavidin arm under static and dynamic conditions}

To understand the specific binding of biotin-graft-PLA NPs with streptavidin as well as with biotin via streptavidin arm, the amount of biotin-graft-PLA NPs or streptavidinincubated biotin-graft-PLA NPs (biotin-graft-PLA NPs-S; $0.1 \mathrm{mg}$ [ $1 \mathrm{~mL}$ of $1 \mathrm{mg} / \mathrm{mL}]$ at room temperature for 30 minutes) adhered on streptavidin- or biotin-coated glass slide was tested under static and dynamic conditions. The pyrene encapsulated NPs were used which allowed testing of the adhered NPs with the fluorescent method. The streptavidin or biotin was coated on glass slide with $0.5 \mathrm{~mL}$ of streptavidin or biotin solution in DMF $(0.2 \mathrm{mg} / \mathrm{mL})$, after evaporation of DMF under vacuum. The binding of biotin-graft-PLA NPs or biotin-graft-PLA NPs-S on streptavidin- or biotin-coated slides was performed at room temperature for 60 minutes with $1 \mathrm{~mL}$ of original NPs (for static condition) or $10 \mathrm{~mL}$ of $10 \times$ distilled water diluted NPs (for dynamic condition) to mimic the in vivo static and dynamic state. A traditional parallel flow chamber ${ }^{25}$ which supplied a shear stress of $\sim 1.0 \mathrm{~Pa}$, middle range value of shear stress in many tissues like blood vessels and bone, ${ }^{26}$ was used to realize dynamic incubation. A streptavidin- or biotin-coated glass slide was fixed in the bottom of the chamber on which the NP solution was flowing. Once binding was complete, the slide was collected, washed with $5 \mathrm{~mL}$ of distilled water three times, and dried under vacuum. DMF ( $5 \mathrm{~mL}$ ) was used to dissolve the adhered NPs and the fluorescent intensity was tested with fluorescence spectrophotometry with the excitation/ emission set of 329/392 nm (LS 50B, PerkinElmer). The PEG-graft-PLA NPs or streptavidin-incubated PEG-graftPLA NPs (PEG-graft-PLA NPs-S; obtained with the same method as biotin-graft-PLA NPs-S) were used as control. The binding of biotin-graft-PLA NPs on streptavidin or biotin-graft-PLA NPs-S on biotin was normalized with PEG-graft-PLA NPs or PEG-graft-PLA NPs-S. Each test was replicated three times. Statistical significance was determined using Student's two-tailed t-test. Statistical significance was defined as $P<0.05$.

\section{Results}

\section{Synthesis of biotin-graft-PLA}

Biotin-graft-PLA was synthesized by reaction of biotinNHS ester with amines in PEG-graft-PLA. Ninhydrin assay showed that the amine in PEG-graft-PLA reacted with biotin. Differential scanning calorimetry showed its glass transition appeared at $30.7^{\circ} \mathrm{C}$, different from the $25.3^{\circ} \mathrm{C}$ of PEG-graft-PLA (Supplement 1). The contact angle was $66^{\circ} \mathrm{C}$, much higher than PEG-graft-PLA which was too low to be detected (Supplement 2) due to biotin exposure. Critical micelle concentration was $7.1 \times 10^{-4} \mathrm{mg} / \mathrm{mL}$ (Figure 2), lower than PEG-graft-PLA $\left(2.0 \times 10^{-3} \mathrm{mg} / \mathrm{mL}\right)$.

\section{Preparation and characterization of biotin-graft-PLA and PEG-graft-PLA NPs}

Biotin-graft-PLA and PEG-graft-PLA NPs encapsulated with naproxen were spherical in shape as observed by transmission electron microscope (Figure 3). Representative size and zeta potential of pyrene-loaded NPs were $297.5 \mathrm{~nm}$ and $-29.13 \mathrm{mV}$ for biotin-graft-PLA NPs and $278.0 \mathrm{~nm}$ and $-23.77 \mathrm{mV}$ for PEG-graft-PLA NPs, representative size and zeta potential of naproxen-loaded NPs were $175 \mathrm{~nm}$ and $-27.35 \mathrm{mV}$ for biotin-graft-PLA NPs and $164.3 \mathrm{~nm}$ and $-26.64 \mathrm{mV}$ for PEG-graft-PLA NPs, 
A

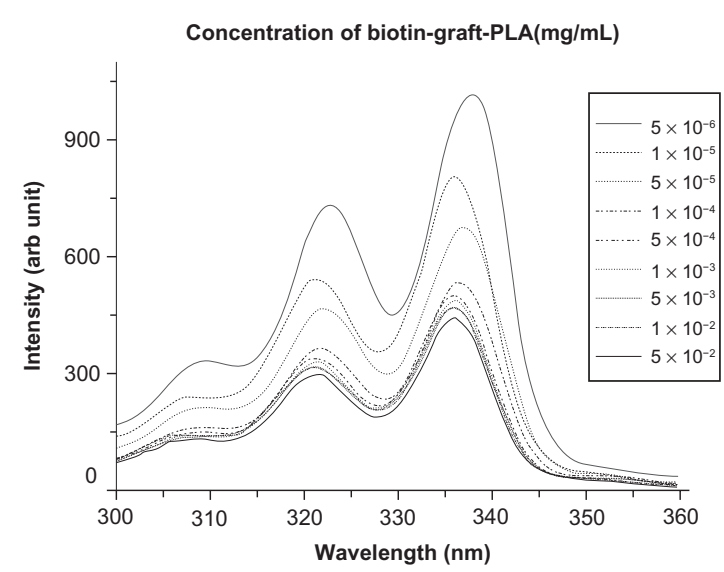

B

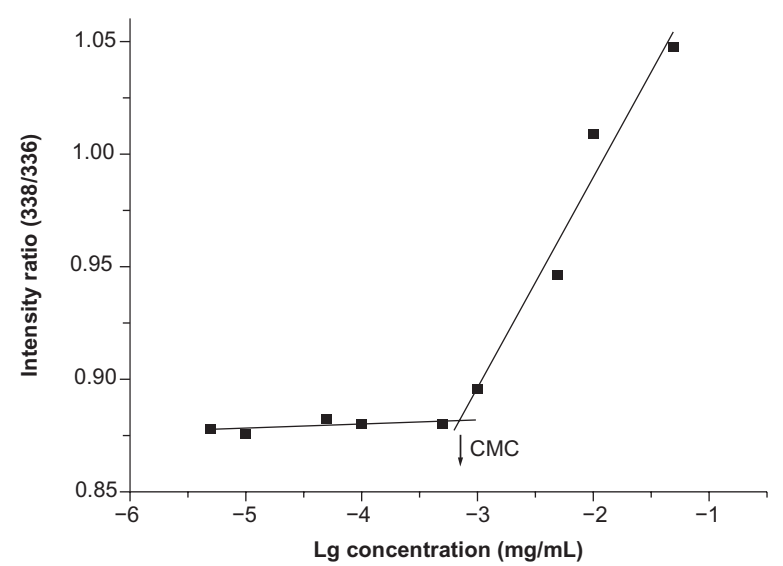

Figure 2 Critical micelle concentration (CMC) determination of biotin-graftpoly(lactic acid) (PLA). (A) Excitation spectra of pyrene from 300-360 nm as a function of biotin-graft-PLA concentration in water. (B) Intensity ratio $(328 / 326)$ of pyrene versus logarithm concentration of poly(ethylene glycol)-graft-PLA. CMC was $7.1 \times 10^{-4} \mathrm{mg} / \mathrm{mL}$, determined by taking the midpoint in the plot of $(\mathbf{B})$.

and representative size and zeta potential of native NPs were $161.6 \mathrm{~nm}$ and $-37.56 \mathrm{mV}$ for biotin-graft-PLA NPs and $114.7 \mathrm{~nm}$ and $-27.84 \mathrm{mV}$ for PEG-graft-PLA. The naproxen-loaded biotin-graft-PLA NPs were stable in dilution for $10 \times, 100 \times$, and $\mathrm{pH}$ range 4.5-10.5 (Figure 4), suggesting its stability under dilution and any $\mathrm{pH}$ change
A

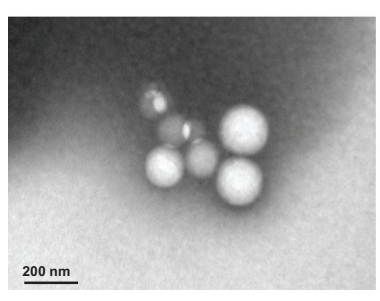

B

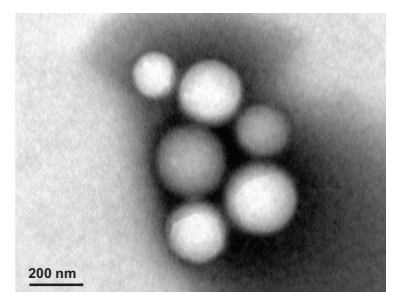

Figure 3 Spherical morphology of native (A) and naproxen-loaded biotin-graft-poly (lactic acid) nanoparticles (B) observed via transmission electron microscope. Scale bar was $200 \mathrm{~nm}$.
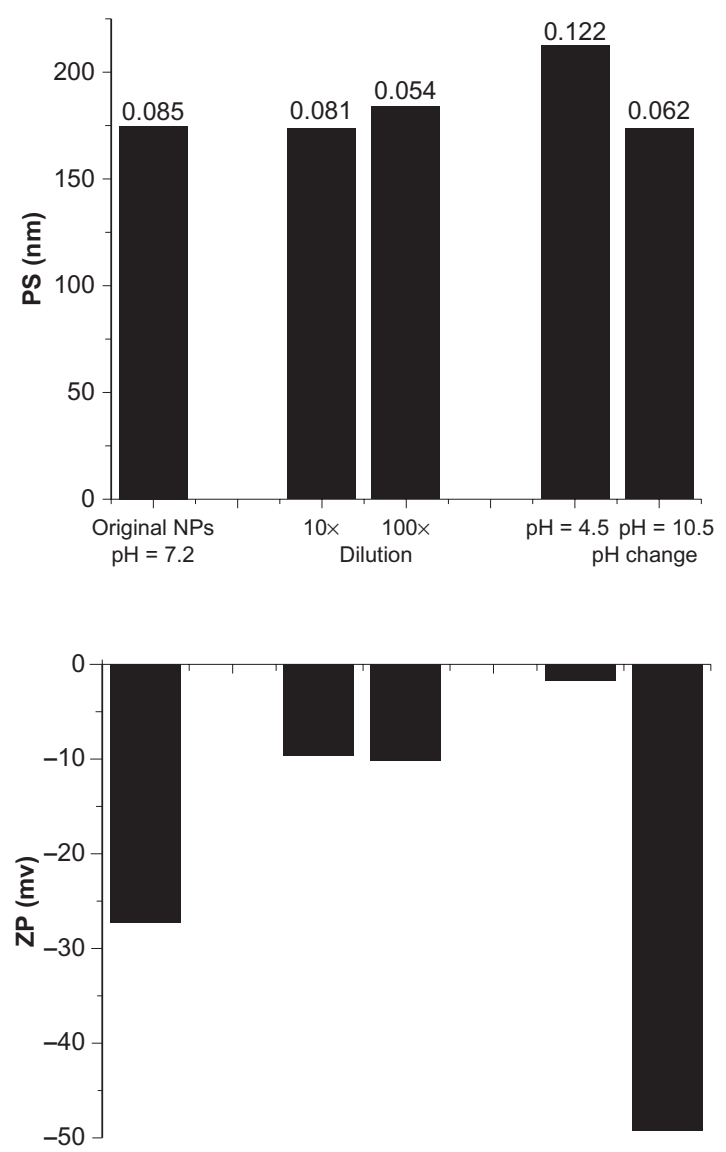

Figure 4 Particle size (PS; top figures), polydispersity (the value above the column on the top figures), and zeta potential (ZP; bottom figures) of naproxen-loaded biotin-graft-poly(lactic acid) nanoparticles (NPs) with/without dilution and $\mathrm{pH}$ changes, tested by dynamic light scatter (Zetasizer Nano S90; Malvern Instruments Ltd, Malvern, UK).

that may result from tissue fluid when introduced into the body.

Encapsulation efficiency of naproxen in biotin-graft-PLA NPs was $51.88 \%$, similar to the $50.2 \%$ of PEG-graft-PLA. Naproxen realized controlled release in 170 hours (Figure 5).

\section{Specific binding of biotin-graft-PLA and its NPs}

The amount of absorbed FITC-streptavidin, and not FITCBSA, was about twice that on biotin-graft-PLA film than on PEG-graft-PLA film, irrespective of whether the polymer was dried at $80 \%$ or $100 \%$ humidity. In detail, the absorbed streptavidin on polymer films was $2.20 \times 10^{-4} \mathrm{~g} / \mathrm{m}^{2}$ on biotingraft-PLA and $1.11 \times 10^{-4} \mathrm{~g} / \mathrm{m}^{2}$ on PEG-graft-PLA when polymers were dried at $80 \%$ humidity; $2.16 \times 10^{-4} \mathrm{~g} / \mathrm{m}^{2}$ on biotin-graft-PLA and $1.09 \times 10^{-4} \mathrm{~g} / \mathrm{m}^{2}$ on PEG-graftPLA when polymers were dried at $100 \%$ humidity. The absorbed BSA on polymer films was $3.50 \times 10^{-4} \mathrm{~g} / \mathrm{m}^{2}$ on 


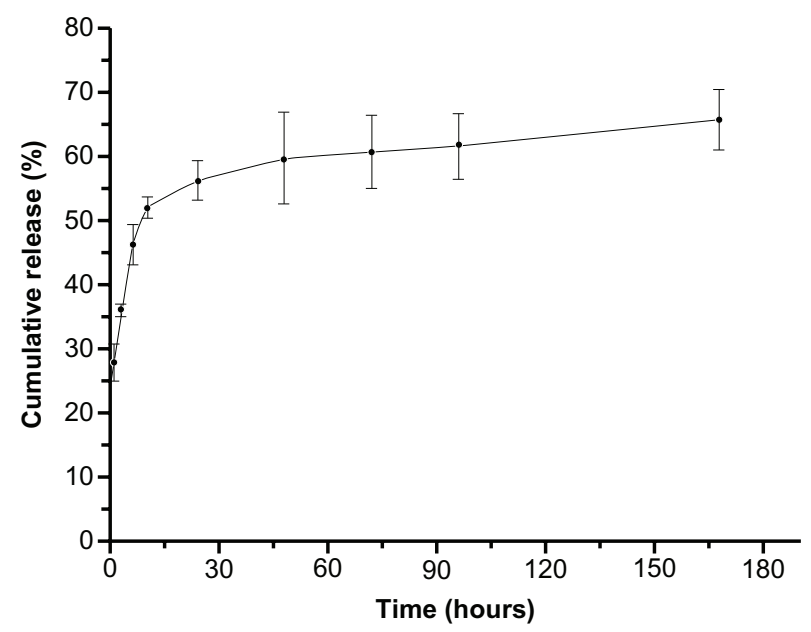

Figure 5 Typical in vitro naproxen release profile from nanoparticles of biotingraft-poly(lactic acid) (time in hours).

biotin-graft-PLA and $3.63 \times 10^{-4} \mathrm{~g} / \mathrm{m}^{2}$ on PEG-graft-PLA when polymers were dried at $80 \%$ humidity; $3.41 \times 10^{-4} \mathrm{~g} / \mathrm{m}^{2}$ on biotin-graft-PLA and $3.59 \times 10^{-4} \mathrm{~g} / \mathrm{m}^{2}$ on PEG-graft-PLA when polymers were dried at $100 \%$ humidity. Due to the proven anti-nonspecific protein property of PEG-graft-PLA polymer from previous experiments, ${ }^{21}$ nonspecific protein resistance and specific streptavidin binding property of biotin-graft-PLA material could be inferred.

Under static and dynamic conditions, biotin-graft-PLA NPs bound 1.6- and 1.4-fold more on streptavidin film compared to PEG-graft-PLA NPs; while 2- and 2.5-fold more biotin-graft-PLA NPs-S adhered on biotin film than PEGgraft-PLA NPs-S (Figure 6). The results showed biotin-graftPLA NPs and biotin-graft-PLA NPs-S bound specifically to

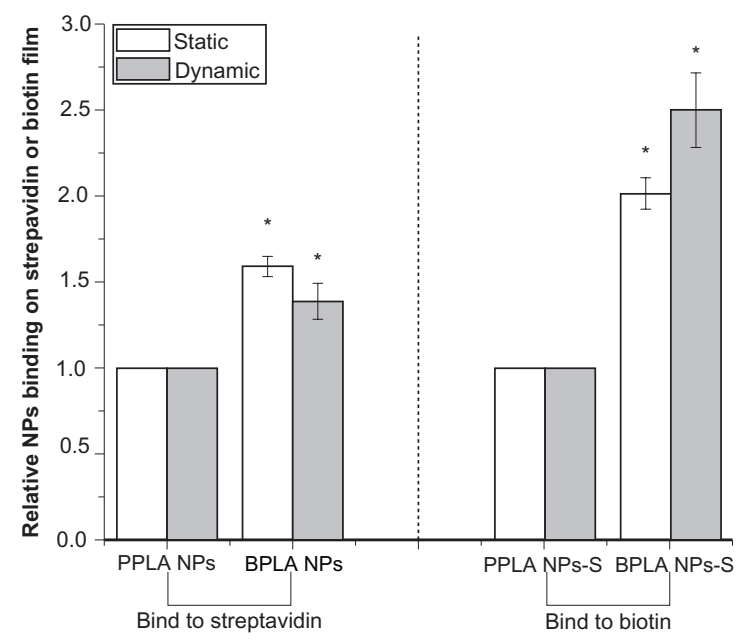

Figure 6 The binding of biotin-graft-poly(lactic acid) (BPLA) and poly(ethylene glycol)-graft-poly(lactic acid) (PPLA) nanoparticles (NPs) on streptavidin and of streptavidin-incubated BPLA NPs (BPLA NPs-S) and streptavidin-incubated PPLA NPs (PPLA NPs-S) on biotin under static and dynamic condition. Note: *Indicates $P<0.05$ compared with PPLA NPs or PPLA NPs-S. streptavidin and biotin respectively, which implied potential targeting of biotin-graft-PLA NPs and biotin-graft-PLA NPs-S to streptavidin and biotin in vivo.

\section{Discussion}

Although several studies have reported self-assembling NPs with attached biotin to the end of PLA via PEG or pluronic spacer, ${ }^{5,6,10,12,13,16-18}$ no study has reported more than one biotin incorporated into one PLA molecule to enhance its binding and potential targeting to streptavidin. In this study, three biotins were linked to one PLA with step by step graft reaction. In addition, to increase biocompatibility a lower MW PEG was used compared with the previously synthesized biotinylated PLA. Biotin-graft-PLA resisted nonspecific protein absorption, inferring a longer stay in the circulation system compared with PLA. The results also demonstrate good surfactivity of biotin-graft-PLA and its feasibility to load and control release naproxen with similar effects as that of previous studies ${ }^{27-29}$ and PEG-graft-PLA. ${ }^{21}$ In particular, specific binding of biotin-graft-PLA NPs with streptavidin and with biotin via a streptavidin arm was confirmed with developed static and dynamic systems.

Biotin was conjugated by activation with DCC and NHS first and then crosslinked with amine of PEG-graft-PLA. DCC has long been used to couple amines and carboxyl groups, ${ }^{30,31}$ and it exhibits high coupling efficiency with hydrolysis of carboxyl groups being the major competing side reaction. A two-step crosslinkage reaction was applied here to reduce the side reaction of DCC and NHS on PEG-graft-PLA. Ninhydrin assay, differential scanning calorimetry, and contact angle tests confirmed the reaction (Supplement 1 and 2). Conjugation of biotin has markedly decreased the hydrophilicity of PEG-graft-PLA (Supplement 2). However, nonspecific protein-resistant and self-assembly properties were maintained due to contained PEGs (Figure 2), which enhanced its feasibility to load medicine via hydrophilic/ hydrophobic interaction and possible longer stay of selfassembled NPs in the circulation system of the body.

During in vitro binding test of streptavidin on biotingraft-PLA film and its NPs on a streptavidin-coated slide, a much lower molar amount of streptavidin than biotin on biotin-graft-PLA was used because it was hoped that biotingraft-PLA and its NPs could target to streptavidin as it would in vivo, considering that the concentration of streptavidin in targeted organ/tissue is generally very low. The results suggest that biotin-graft-PLA and its NPs could target to a streptavidin-containing position even at low concentrations (Figure 6). Similarly, much lower molar amount of streptavidin 
than biotin in combination of biotin-graft-PLA NPs-S with biotin was applied where it was still found that biotin-graftPLA NPs-S bound specifically with biotin, suggesting the biotin-graft-PLA NPs-S could target to a biotin-containing position. In addition, it was found that biotin-graft-PLA and PEG-graft-PLA films dried in high humidity (100\%) absorbed less streptavidin and BSA compared with films dried in low humidity ( $80 \%)$. The reason may be that PEG extended more on the surface of film during drying in high humidity which expressed better protein resistance. It was also found that BSA absorbed about 1.6-3.3-fold more than streptavidin both on biotin-graft-PLA and PEG-graft-PLA films, which was thought to be induced by differences in protein structure.

PEG-graft-PLA polymer bioactivated with biotin first and then formed NPs by self-assembly method (termed as two-step bioactivated PLA NPs) in this study, even though biotin could be directly linked to the NPs of PEG-graft-PLA via the same reaction (termed as one-step bioactivated PLA NPs). This was because the aim was to prepare bioactive PLA material that could be used in drug delivery as well as in tissue engineering. Biotin on the biotin-graft-PLA could be inside or outside when self-assembled into NPs. However, according to in vitro binding tests of NPs with streptavidin (Figure 6), it was inferred that biotin appeared at least partly outside of biotin-graft-PLA NPs. But whether the two-step or the one-step bioactivated PLA NPs contained more outside biotin needs further study. No matter the process, a more biotin-conjugated PLA was developed, which provided opportunity to have more outside biotin in its NPs and a better potential targeting function compared with the previously reported biotinylated PLA.

Biotin has been conjugated to the end of PEG-block-PLA $(\mathrm{PEG} M \mathrm{MW} \geq 3800)^{13}$ and received bioactivity via the interaction of biotin/avidin pair. Attachment of biotinylated arginineglycine-aspartic acid via avidin spacer in biotin-block-PLA improved cell adhesion ${ }^{10}$ and proliferation. ${ }^{18}$ Self-assembled NPs of biotinylated PEG-block-PLA plus PEG-block-PLA for paclitaxel entrapment targeted to brain cancer cells in vitro, via the combination of biotin and neutravidin, ${ }^{13}$ achieved entrapment efficiency over $90 \%$ and controlled release in 8 hours. The biotinylated pluronic-block-PLA self-assembled NPs showed potential targeting function by way of biotin-avidin interaction. ${ }^{14}$ The biotin-graft-PLA NPs in this study received entrapment and controlled release of naproxen for over $50 \%$ and 170 hours. Furthermore, the more conjugated biotin in biotin-graft-PLA along with its good biocompatibility may entrust its application in targeted drug delivery, even though further confirmation is needed. For example, biotin-graft-PLA
NPs can be used to target to acute and chronic inflammatory tissue, where selectins are localized and carefully regulated expressed by conjugation with biotinylated sialyl-Lewis ${ }^{\mathrm{X}}$, a highly specific receptor for selectin via streptavidin arm, so as to reduce the gastrointestinal side effects such as ulcer caused by anti-inflammatory drugs. ${ }^{32}$ Similarly NPs can target to brain glioma by conjugation with biotinylated transferrin, a monomeric glycoprotein with receptor that is overexpressed in brain capillary endothelium and at the surface of proliferating cells such as brain tumor cells, especially glioblastoma multiforme, ${ }^{16}$ via a streptavidin arm. In addition, due to the appearance of biotin on outside biotin-graft-PLA NPs and the encapsulation for hydrophobic fluorescent naproxen and pyrene, the application of NPs in vivo detection system by way of fluorescent and optical imaging methods would be expected. ${ }^{17,33}$ Biotin-graft-PLA could also be used as coating on tissue engineering substrate or directly used to fabricate substrate to control growth of cells, especially for the attachment of biotinylated cells. ${ }^{34}$

\section{Conclusion}

Biotin-graft-PLA, with three biotins in one polymer molecule synthesized using a low MW PEG (MW 1900), showed good nonspecific protein resistance and specific streptavidin binding property. It self-assembled into NPs during which naproxen was loaded in and realized encapsulation efficiency of $51.88 \%$ and controlled release within 170 hours. Biotin-graft-PLA NPs bound specifically to streptavidin and to biotin using streptavidin arm in both static and dynamic conditions in vitro.

\section{Acknowledgments}

PJ thanks National Science Foundation (Beijing Office, China; No. 10972243, 30300084, and 30870606), “111 Project" of China (No. B06023), and Key Laboratory of Microgravity, Institute of Mechanics, Chinese Academy of Sciences for supporting this research.

\section{Disclosure}

The authors report no conflicts of interest in this work.

\section{References}

1. Griffith LG, Naughton G. Tissue engineering - current challenges and expanding opportunities. Science. 2002;295(5557):1009-1014.

2. Hench LL, Polak JM. Third-generation biomedical materials. Science. 2002;295(5557):1014-1017.

3. Farokhzad OC, Langer R. Nanomedicine: developing smarter therapeutic and diagnostic modalities. Adv Drug Deliv Rev. 2006;58(14) 1456-1459.

4. Clapper JD, Pearce ME, Guymon CA, Salem AK. Biotinylated biodegradable nanotemplated hydrogel networks for cell interactive applications. Biomacromolecules. 2008;9(4):1188-1194. 
5. Weiss B, Schneider M, Muys L, et al. Coupling of biotin-(poly(ethylene glycol))amine to poly(D,L-lactide-co-glycolide) nanoparticles for versatile surface modification. Bioconjug Chem. 2007;18(4): 1087-1094.

6. Nobs L, Buchegger F, Gurny R, Allemann E. Biodegradable nanoparticles for direct or two-step tumor immunotargeting. Bioconjug Chem. 2006;17(1):139-145.

7. Caliceti P, Chinol M, Roldo M, et al. Poly(ethylene glycol)-avidin bioconjugates: suitable candidates for tumor pretargeting. J Control Release. 2002;83(1):97-108.

8. Green NM. A spectrophotometric assay for avidin and biotin based on binding of dyes by avidin. Biochem J. 1965;94:23C-24C.

9. Lindqvist Y, Schneider G. Protein-biotin interactions. Curr Opin Struct Biol. 1996;6(6):798-803.

10. Cannizzaro SM, Padera RF, Langer R, et al. A novel biotinylated degradable polymer for cell-interactive applications. Biotechnol Bioeng. 1998;58(5):529-535.

11. Griffith LG. Polymeric biomaterials. Acta Materialia. 2000;48(1): 263-277.

12. Salem AK, Cannizzaro SM, Davies MC, et al. Synthesis and characterisation of a degradable poly(lactic acid)-poly(ethylene glycol) copolymer with biotinylated end groups. Biomacromolecules. 2001; 2(2):575-580.

13. Pulkkinen M, Pikkarainen J, Wirth T, et al. Three-step tumor targeting of paclitaxel using biotinylated PLA-PEG nanoparticles and avidin-biotin technology: formulation development and in vitro anticancer activity. Eur J Pharm Biopharm. 2008;70(1):66-74.

14. Xiong XY, Gong YC, Li ZL, Li YP, Guo L. Active targeting behaviors of biotinylated pluronic/poly(lactic acid) nanoparticles in vitro through three-step biotin-avidin interaction. J Biomater Sci Polym Ed. 2011;22(12):1607-1619.

15. Jeon SI, Lee JH, Andrade JD, de Gennes PG. Protein surface interactions in the presence of polyethylene oxide: I. Simplified theory. $J$ Colloid Interface Sci. 1991;142(1):149-158.

16. Ren WH, Chang J, Yan $\mathrm{CH}$, et al. Development of transferrin functionalized poly(ethylene glycol)/poly(lactic acid) amphiphilic block copolymeric micelles as a potential delivery system targeting brain glioma. J Mater Sci Mater Med. 2010;21(9):2673-2681.

17. Xu JS, Huang J, Qin R, et al. Synthesizing and binding dual-mode poly (lactic-co-glycolic acid) (PLGA) nanobubbles for cancer targeting and imaging. Biomaterials. 2010;31(7):1716-1722.

18. Yu G, Ji J, Zhu H, Shen J. Poly(D,L-lactic acid)-block-(ligand-tethered poly(ethylene glycol)) copolymers as surface additives for promoting chondrocyte attachment and growth. J Biomed Mater Res B Appl Biomater. 2006;76(1):64-75.
19. Merrill EW, Salzman EW. Polyethylene oxide as a biomaterial. ASAIOJ. $1983 ; 6: 60-64$.

20. Wen J, Kim GJ, Leong KW. Poly(D,L-lactide-co-ethyl ethylene phosphate)s as new drug carriers. J Control Release. 2003;92(1-2):39-48.

21. Pan J, Zhao M, Liu Y, Wang B, Mi L, Yang L. Development of a new poly(ethylene glycol)-graft-poly(D,L-lactic acid) as potential drug carriers. J Biomed Mater Res A. 2009;89(1):160-167.

22. Wang B, Jiang W, Yan H, et al. Novel PEG-graft-PLA nanoparticles with potential for encapsulate and controlled release hydrophobic and hydrophilic medications in aqueous medium. Int $J$ Nanomedicine. 2011;6:1443-1451.

23. Pan J, Wang Y, Qin S, Zhang B, Luo Y. Grafting reaction of poly(D,L) lactic acid with maleic anhydride and hexanediamine to introduce more reactive groups in its bulk. J Biomed Mater Res B Appl Biomater. 2005; 74(1):476-480

24. Chiellini E, Solaro R. Biodegradable polymer materials. Adv Mater. 1996;8:305-313.

25. Hung CT, Pollack SR, Reilly TM, Brighton CT. Real-time calcium response of cultured bone cells to fluid flow. Clin Orthop Relat Res. 1995;313:256-269.

26. Weinbaum S, Cowin SC, Zeng Y. A model for the excitation of osteocytes by mechanical loading-induced bone fluid shear stresses. J Biomech. 1994;27(3):339-360.

27. JavadzadehY, Ahadi F, Davaran S, Mohammadi G, SabzevariA, Adibkia K. Preparation and physicochemical characterization of naproxen-PLGA nanoparticles. Colloids Surf B Biointerfaces. 2010;81(2):498-502.

28. Rodrigues MR, Lanzarini CM, Ricci-Junior E. Preparation, in vitro characterization and in vivo release of naproxen loaded in poly-caprolactone nanoparticles. Pharm Dev Technol. 2011;16(1):12-21.

29. Puglia C, Bonina F, Rizza L, et al. Evaluation of percutaneous absorption of naproxen from different liposomal formulations. J Pharm Sci. 2010;99(6):2819-2829.

30. Hermanson GT. Bioconjugate Techniques. Rockford, IL: Academic Press; 1996.

31. Rich DH, Singh J. The carbodiimide method. In: Gross J, Meienhofer J, editors. The Peptides: Analysis, Synthesis, Biology. New York: Academic Press; 1979:241-314.

32. Eniola AO, Hammer DA. Artificial polymeric cells for targeted drug delivery. J Control Release. 2003;87(1-3):15-22.

33. Tosi G, Rivasi F, Gandolfi F, Costantino L, Vandelli MA, Forni F. Conjugated poly(D,L-lactide-co-glycolide) for the preparation of in vivo detectable nanoparticles. Biomaterials. 2005;26(19):4189-4195.

34. Sinclair J, Salem AK. Rapid localized cell trapping on biodegradable polymers using cell surface derivatization and microfluidic networking. Biomaterials. 2006;27(9):2090-2094. 


\section{Supplement figures}

A

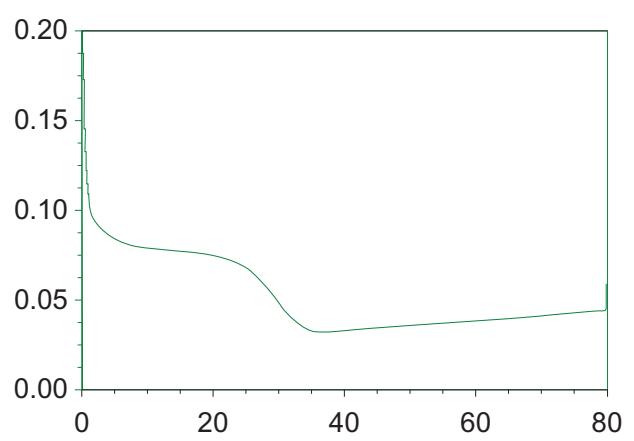

B

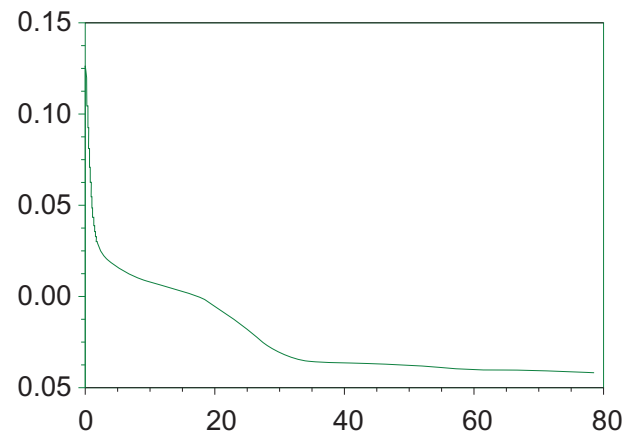

Figure SI Differential scanning calorimetry curves of biotin-graft-poly(lactic acid) (A) and poly(ethylene glycol)-graft-poly(lactic acid) (B).

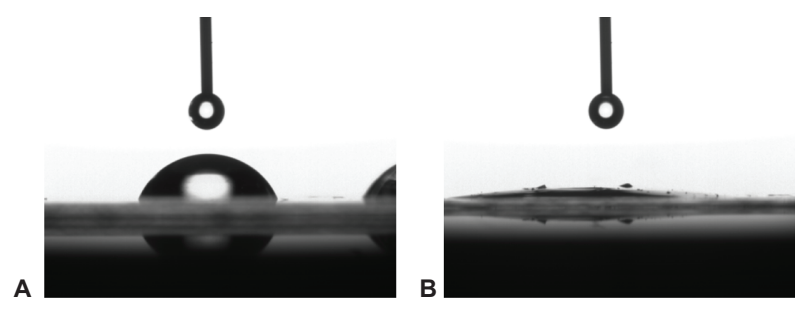

Figure $\mathbf{S 2}$ The contact angle comparison of biotin-graft-poly(lactic acid) (A) and poly(ethylene glycol)-graft-poly(lactic acid) (B).

\section{Publish your work in this journal}

The International Journal of Nanomedicine is an international, peerreviewed journal focusing on the application of nanotechnology in diagnostics, therapeutics, and drug delivery systems throughou the biomedical field. This journal is indexed on PubMed Central,

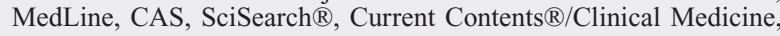

Journal Citation Reports/Science Edition, EMBase, Scopus and the Elsevier Bibliographic databases. The manuscript management system is completely online and includes a very quick and fair peer-review system, which is all easy to use. Visit http://www.dovepress.com/ testimonials.php to read real quotes from published authors.

\footnotetext{
Submit your manuscript here: http://www.dovepress.com/international-journal-of-nanomedicine-journal
} 